http://dx.doi.org/10.23925/2176-2767.2019v64p362-370

Data recebimento: 11/12/2018 Data Aprovação:29/01/2019

RESENHA

\title{
MEMÓRIAS SOLDADESCAS DE UM BRASIL HOLANDÊS
}

ANA PAULA NUNES DA SILVA ${ }^{1}$

HAJSTRUP, Peter Hansen. Viagem ao Brasil (1644-1654) - O diário de um soldado dinamarquês a serviço da Companhia das Índias Ocidentais. Organizadores: Benjamin Nicolaas Teensma, Bruno Romero Ferreira Miranda, Lucia Furquim Werneck Xavier. Recife: Cepe, 2016. 130 pg.

A Companhia Editora de Pernambuco trouxe à comunidade dos pesquisadores brasileiros uma importante contribuição: trata-se da publicação do livro Viagem ao Brasil (1644-1654) - O diário de um soldado dinamarquês a serviço da Companbia das Índias Ocidentais, publicado em 2016. A obra é fruto de um minucioso trabalho de pesquisa e tradução, e traz ao leitor a oportunidade de conhecer um raro relato, em forma de diário, escrito por um soldado chamado Peter Hansen (1624-1672). Hansen - um militar de baixa patente que viveu de perto as disputas coloniais entre os Impérios europeus do século XVII - foi funcionário da Companhia das Índias Ocidentais e viveu no Brasil entre 1644 e 1654, em um período de ocupação neerlandesa em territórios do atual Nordeste do país, que ficou conhecido como 'Brasil Holandês' (1630-1654). 
O livro é resultado de uma parceria entre três organizadores ${ }^{2}$, todos historiadores, e foi dividido em três partes. A Apresentação - escrita por Bruno Romero Ferreira Miranda (também o responsável por escrever as notas do diário de Hansen); um estudo introdutório intitulado $A$ carreira de um soldado de Schleswig (1644-1654), escrito por Benjamin Nicolaas Teensma (também responsável por traduzir o diário de Hansen para o português); e os relatos do diário escrito por Peter Hansen e intitulado, por ele mesmo, como Memorial e Jornal de tudo que passou na minha viagem, registrado com dias e datas a partir de 1643.

$\mathrm{Na}$ Apresentação o historiador Bruno Miranda busca, além de apresentar o texto principal do livro, contextualizar historicamente o seu autor, Peter Hansen, e destacar a importância deste documento como "um dos raros relatos de militares europeus que estiveram no Brasil no século XVII” (MIRANDA, 2016, p. 9), principalmente por se tratar das memórias de um oficial de baixa patente. De acordo com Miranda, este diário é ainda mais precioso e peculiar pelo fato de que originalmente não ter passado pelas mãos de um editor e nem ter sido publicado até a década de 1990.

Peter Hansen foi um dos milhares de soldados recrutados pelo exército da Companhia Neerlandesa das Índias Ocidentais (WIC) a fim de combater no Brasil. O seu manuscrito do século XVII encontra-se atualmente no Arquivo Nacional de Schleswig-Holstein, em Schleswig, na Alemanha. Alguns historiadores holandeses, a partir da análise da caligrafia do texto, acreditam que a escrita não seja do próprio Hansen, mas talvez de um hábil escrivão do século XVIII, contratado para copiar esses relatos a partir dos originais. É importante mencionar que este documento não é um diário comum, mas sim uma espécie de compilação de diversos assuntos e 
anotações. Dentro dessa gama de anotações, constam os relatos da sua viagem e estada de dez anos no Brasil, a serviço da WIC, como militar em diferentes funções e postos de trabalho.

A parte referente ao Brasil ocupa cerca da metade do todo o manuscrito. É justamente essa parte do diário que o livro contém, devidamente traduzida ao português. Trata-se de um documento bastante heterogêneo e, desta forma, "os textos de Peter Hansen constituem fonte preciosa sobre a vida no século XVII e servem não apenas como um documento para o estudo do domínio neerlandês no Brasil, mas também ao interesse particular de quem estuda a história social e as mentalidades no início da era moderna” (MIRANDA, 2016, p. 16), mesmo sendo escrito por um homem de baixa escolaridade, com relatos descritos de forma simples e resumida.

No estudo introdutório, uma nota teórica que antecede o diário, intitulado A carreira de um soldado de Schleswig (1644-1654), o historiador neerlandês Benjamin Nicolaas Teensma explora de forma acurada a biografia de Peter Hansen, bem como o contexto histórico no qual ele viveu. São dados fundamentais para que o leitor possa se situar a respeito de quem foi Hansen, e o que fez ao longo de sua vida, especialmente durante o período em que esteve no Brasil, foco deste livro.

A história de Peter Hansen começa em 1624, em um pequeno vilarejo chamado Hajstrup, na Dinamarca. Aos 19 anos saiu da casa dos pais para procurar melhores oportunidades de vida em uma cidade maior. Seguiu primeiramente para Copenhague, onde trabalhou por um tempo no Real Armazém dos víveres do rei Cristiano IV e, mais tarde, já em Amsterdã, conseguiu uma vaga no exército da Companhia Neerlandesa das 
Índias Ocidentais (WIC), circunstância que o conduziu ao Brasil. Hansen chegou a Pernambuco em fins de 1644, tendo desembarcado no porto de Recife, o mais importante e estratégico do Brasil Holandês, que compreendia em seus domínios boa parte das chamadas 'Capitanias do Norte' no período colonial - território que atualmente corresponde à grande parte do Nordeste brasileiro.

Desde o início sua vida nos trópicos foi agitada. Mesmo sem ter recebido treinamento militar, participou diretamente de uma série de conflitos e guerras que foram travadas entre portugueses e holandeses pela posse dos territórios açucareiros que a WIC manteve por mais de duas décadas sob seu domínio. De acordo com Teensma, Peter "participou das batalhas de Tabocas (1645), de Casa Forte (1645) e dos Guararapes (1648)" (TEENSMA, 2016, p. 21). Sobre elas, "Hansen menciona apenas superficialmente os muitos desenvolvimentos políticos e militares que assolaram o Brasil neerlandês a partir de 1645" (TEENSMA, 2016, p. 24). Os conflitos de Peter Hansen não se resumem às refregas da WIC. Sua história também foi marcada por uma série de bebedeiras e brigas nas quais se envolveu, de acordo com seus próprios relatos. Tratava-se, podemos deduzir, de um homem de temperamento explosivo. Boa parte destes conflitos acarretou em prisões e julgamentos pelas autoridades militares neerlandesas.

Durante sua estadia no Brasil, ele passou por diferentes regiões e prestou serviço em várias fortificações, em territórios que hoje pertencem aos estados de Pernambuco, Rio Grande do Norte, Paraíba e Ceará. Contudo, sua maior estadia foi no Forte Ceulen - onde permaneceu até a 
rendição da Companhia, em 1654 - atualmente conhecido como Forte dos Reis Magos, localizado em Natal, capital do Rio Grande do Norte.

Mesmo sem nunca ter alcançado uma alta patente no exército, Hansen teve uma atuação de certa importância ao longo da sua carreira como militar no Brasil. Ele compôs, por exemplo, a patrulha que fora prender o rebelde João Fernandes Vieira, uma das grandes lideranças da Restauração Pernambucana. Para realizar missões como esta Hansen saia da segurança das fortificações e se embrenhava mata à dentro rumo a um interior até então pouco explorado, morada de negros fugidos e de indígenas do sertão de várias etnias diferentes, mas chamados pejorativamente de 'tapuias' pelos indígenas tupis (seus inimigos) e pelos colonizadores. Eram considerados os mais perigosos e selvagens dentre os indígenas.

Nos seus relatos ele dedicou pouca atenção aos negros, mas sobre os indígenas narrou diversas situações. Havia um contato mais próximo entre os colonizadores e os tupis, mas “os neerlandeses também agiam muito cautelosamente com os tapuias, principalmente porque, de fato, os primeiros só permaneceram na capitania do Rio Grande devido à proteção dos segundos" (TEENSMA, 2016, p. 30). Era uma relação de negociação e tensão entre eles, mediada por homens da WIC que conseguiam se comunicar com os indígenas na língua deles. Hansen esteve à frente dessa função em algumas ocasiões.

$\mathrm{Na}$ terceira parte do livro encontra-se o diário de Hansen, intitulado Memorial e Jornal de tudo que passou na minha viagem, registrado com dias e datas a partir de 1643. O relato é dividido por anos [de 1643 até 1654] e começa com anotações sobre 1643, quando Hansen saiu da casa dos pais rumo à 
Amsterdã. No ano seguinte, depois de semanas no mar, o soldado da WIC chega a Pernambuco, em dezembro de 1644. "A 16 do dito, os soldados em número de 42 com seu comandante foram buscados, no navio, por uma grande chalupa, levados à cidade do Recife [...]” (HANSEN, 2016, p. 49).

Em trecho de 1645 ele narra o dia seguinte após uma batalha contra os portugueses: “[...] nos refizemos um pouco, embora não recebêssemos outra coisa de comer senão algumas laranjas, maracujás e outras frutas, e açúcar e garapa misturada com água. Bebemos isso, e por essa razão a maior parte dos nossos apanhou uma diarreia sangrenta, da qual muitos morreram” (HANSEN, 2016, p. 55). Em 1647 uma cena brutal: “A 17 de setembro, quando o inimigo estava voltado para o Rio Grande, capturaram seis homens nossos [...] Mataram-nos em seguida, depois de torturá-los tanto que mal pareciam seres humanos [...] fomos enterrá-los e precisamos recolher os pedaços deles para deitá-los na sepultura" (HANSEN, 2016, p. 68). São diversos relatos como esse, nos quais o autor nos revela cenas de muitas privações e batalhas sangrentas, com milhares de baixas de ambos os lados. Relatos impactantes sobre o cotidiano de combatentes que viveram às duras penas, mas que também foram cruéis algozes de indígenas, caboclos e negros, abatidos aos milhares durante os conflitos.

Consta em 1648 um interessante relato sobre um dos contatos de Hansen com os tapuias: “[...] fui mandado à aldeia de Silva dos selvagens, ou tapuias, para falar com eles, e ler e traduzir uma carta redigida em português por parte dos brasilianos que sofriam grandes danos deles nas roças.” (HANSEN, 2016, p. 70). Hansen aparece aqui como mediador entre os tapuias e os brasilianos [indígenas de língua tupi]. 
"Quando me encontrei com o rei deles, Nhanduí, e li a ele o conteúdo da carta na qual ele era proibido por nossos senhores e Alto Conselho de causar danos aos brasilianos, ele ficou muito irritado. Até tive a impressão de que queria me matar e devorar" (HANSEN, 2016, p. 71).

Esse episódio teve um fim pacífico, pois na conversa foram expostos motivos de interesse dos tapuias pela paz e Hansen saiu de lá amigavelmente. Cenas como essa são valiosas para estudos sobre as relações entre colonizadores e indígenas. Corrobora-se aqui a ideia aventada pela historiografia de que os holandeses foram mais habilidosos e bem sucedidos nas suas tratativas com os indígenas, em especial os tapuias, do que os portugueses.

Em 1649 Hansen ele relata de forma bastante sucinta a segunda batalha dos Guararapes:

"A 7 de fevereiro, o senhor general Sigismund von Schoppe saiu em expedição contra os portugueses com 4000 homens, mas foi derrotado pelo inimigo, deixando no campo 1400 mortos e 200 presos, com toda a munição e artilharia de campanha" (HANSEN, 2016, p. 72).

Com essa dura derrota dos holandeses, praticamente se definiu o cenário da derrocada holandesa. De acordo com Evaldo Cabral de Mello: "Para fins ofensivos, já não existia o exército da WIC" ${ }^{3}$. O 'Brasil Holandês' marchava rumo ao fim, e poucos anos depois, os portugueses finalmente conseguiram reaver a posse total dos seus territórios coloniais na América.

Por fim, no ano de 1654, sobre seus últimos momentos no Brasil, Hansen fez um relato mais extenso desses acontecimentos finais, que ficaram marcados pelo cerco total da cidade do Recife pelos colonos lusobrasileiros e, também, pela rendição e evacuação dos neerlandeses dos 
territórios ocupados. Peter Hansen embarcou em uma das várias caravelas que partiram do Brasil rumo ao Caribe em fevereiro deste ano.

Depois de uma viagem de alguns meses pelas Antilhas, em junho de 1654 os navios seguiram rumo aos Países Baixos. Cinquenta dias depois, aportaram em Vlissingen, na Holanda. Após algumas semanas, Peter Hansen retornou à Hajstrup, sua cidade natal, concluindo assim sua saga, que durou onze anos no total, passando por paragens do Velho Continente e do Novo Mundo.

'Viagem ao Brasil' é, sem dúvida, um livro bastante relevante para a historiografia do Brasil Holandês, pois contribui trazendo à tona um relato inédito sobre esse período, o que de certa forma ajuda também a reavivar o interesse dos estudiosos sobre o tema e a angariar novas possibilidades de pesquisa. É preciso, portanto, congratular a decisão de publicar uma obra como essa, que coloca na agenda atual um tema que, apesar de ser um capítulo consagrado da nossa história, muitas vezes acaba restrito a circuitos locais de pesquisa. Uma obra como essa pode circular pelo Brasil e atingir um potencial público de interesse.

Vale mencionar ainda que, analisando a natureza do conteúdo desta obra, é possível dizer que se destina a leitores que tenham minimamente algum conhecimento sobre o tema e o período em questão, caso contrário, a leitura pode ser bastante prejudicada. Contudo, as notas de rodapé trazem informações importantes para situar o leitor frente aos episódios e personagens aos quais Hansen se refere, tendo como fonte a historiografia clássica sobre o Brasil Holandês, com nomes consagrados como José Antônio Gonsalves de Mello, Evaldo Cabral de Mello, e Charles Boxer, além de historiadores holandeses especialistas no tema. Nas notas, o 
historiador Bruno Miranda também fornece informações que auxiliam na compreensão da tradução de alguns termos, na localização geográfica de certos eventos e, até mesmo, explicando algumas passagens da narrativa.

Em suma, trata-se de uma obra valiosa para historiadores e públicos afins, que conta com um projeto editorial e gráfico cuidadoso e de muito bom gosto, com imagens bem selecionadas, que ajudam o leitor a se remeter, com mais 'poesia' e cor, ao mundo narrado por Peter Hansen.

${ }^{1}$ Graduanda em História pela Pontifícia Universidade Católica de São Paulo (PUC-SP) e bolsista de iniciação científica pelo CNPq com a pesquisa: Nos mais recônditos confins de dentro: Sobre a construção das representações do sertão nordestino e a formação de uma nova sociedade colonial (séculos XVII-XVIII)'. Número do ORCID: https://orcid.org/0000-0002-0957-0822

2 Benjamin Nicolaas Teensma é professor emérito da seção de Português do Departamento de Línguas e Culturas da América Latina da Universidade de Leiden. Doutor pela Universiteit van Amsterdam, é também associado correspondente do Instituto Arqueológico, Histórico e Geográfico Pernambucano, e já traduziu diversos textos referentes ao período neerlandês no Brasil. Bruno Romero Ferreira Miranda é professor do Departamento de História da Universidade Federal Rural de Pernambuco. Doutor pela Universiteit Leiden e também membro do Instituto Arqueológico, Histórico e Geográfico Pernambucano. Lucia Furquim Werneck Xavier é mestre em história pela Erasmus Universiteit.

${ }^{3}$ MELLO, E. C. de. O Brasil Holandês. São Paulo: Penguin Classics, 2010. p. 457. 